\title{
Solar storms may trigger sperm whale strandings: explanation approaches for multiple strandings in the North Sea in 2016
}

\author{
Klaus Heinrich Vanselow', Sven Jacobsen ${ }^{2}$, Chris Hall ${ }^{3}$ and Stefan Garthe' \\ ${ }^{1}$ Research and Technology Centre (FTZ), Kiel University, Hafentörn 1, 25761 Büsum, Germany e-mail: vanselow@ftz-west. \\ uni-kiel.de \\ ${ }^{2}$ German Aerospace Centre (DLR), Remote Sensing Technology Institute, SAR Signal Processing, Maritime Safety and \\ Security Lab, Henrich-Focke-Straße 4, 28199 Bremen, Germany \\ ${ }^{3}$ Tromso Geophysical Observatory, UiT - The Arctic University of Norway, 9037 Tromsø, Norway
}

\begin{abstract}
The Earth's atmosphere and the Earth's magnetic field protects local life by shielding us against Solar particle flows, just like the sun's magnetic field deflects cosmic particle radiation. Generally, magnetic fields can affect terrestrial life such as migrating animals. Thus, terrestrial life is connected to astronomical interrelations between different magnetic fields, particle flows and radiation. Mass strandings of whales have often been documented, but their causes and underlying mechanisms remain unclear. We investigated the possible reasons for this phenomenon based on a series of strandings of 29 male, mostly bachelor, sperm whales (Physeter macrocephalus) in the southern North Sea in early 2016. Whales' magnetic sense may play an important role in orientation and migration, and strandings may thus be triggered by geomagnetic storms. This approach is supported by the following: (1) disruptions of the Earth's magnetic field by Solar storms can last about 1 day and lead to short-term magnetic latitude changes corresponding to shifts of up to $460 \mathrm{~km}$; (2) many of these disruptions are of a similar magnitude to more permanent geomagnetic anomalies; (3) geomagnetic anomalies in the area north of the North Sea are 50-150 km in diameter; and (4) sperm whales swim about $100 \mathrm{~km} \mathrm{day}^{-1}$, and may thus be unable to distinguish between these phenomena. Sperm whales spend their early, non-breeding years in lower latitudes, where magnetic disruptions by the sun are weak and thus lack experience of this phenomenon. 'Naïve' whales may therefore become disoriented in the southern Norwegian Sea as a result of failing to adopt alternative navigation systems in time and becoming stranded in the shallow North Sea.
\end{abstract}

Received 16 February 2017, accepted 2 July 2017, first published online 15 August 2017

Key words: geomagnetic anomaly, magnetic field, migration, North Sea, Norwegian Sea, Physeter macrocephalus, Solar activity, Solar storm, sperm whale, stranding.

\section{Introduction}

Multiple strandings of sperm whales (Physeter macrocephalus), defined as two or more animals stranded at about the same time, in or near the same place, are infrequent but worldwide occurrences. Sperm whale strandings (single animals or groups) have been documented in the North Sea since the Middle Ages (Smeenk 1997; Vanselow \& Ricklefs 2005; Pierce et al. 2007). The latest mass stranding occurred between 8 January and 4 February 2016, when 29 male sperm whales were found stranded along the coasts of Germany, the Netherlands, Great Britain and France, including 16 along the German coast. Autopsies were carried out on 22 animals, which all appeared to have good nutritional status and to be suffering from no debilitating illnesses. Apart from food remains, the gastrointestinal tracts of nine animals contained marine debris, though this was not considered to have been lethal (Unger et al. 2016).

Sperm whales live in deep, warm-to-temperate waters in all oceans. Groups of females and young stay at lower latitudes and are found in the eastern Atlantic as far north as about $40^{\circ} \mathrm{N}$, e.g., around the Azores. After reaching independence at around 10-15 years, young bulls leaves the family unit and form 'bachelor groups', which then migrate into northern waters, where they undertake seasonal movements. Old bulls also move out of the breeding areas again, mostly on their own. Observations document that the same sperm whales sighted first near the Azores were seen years later near Tromsø (Norway) (Steiner et al. 2012). One sperm whale migration route passes west of the British Isles and through the Faroe-Shetland Channel into the Norwegian Sea (Evans 1997), where they are attracted by huge quantities of squid (Gonatus fabricii), which comprises their main food source in the area during the winter and spring (Evans 1997; Smeenk 1997; Pierce et al. 2007). Although sperm whales do not normally occur in the North Sea because of a lack of suitable habitat, some animals enter the North Sea, probably on their way south between Shetland and Norway, where they may encounter difficulties. These animals appear disorientated and may eventually become stranded, often still alive (see 
Tougaard \& Kinze (1999) for a description of the erratic behaviour of stranding sperm whales). The stomachs of the stranded whales often contain masses of Gonatus beaks; the species does normally not occur in the North Sea, thus confirming that the animals were travelling south (Pierce et al. 2007).

Several theories have been put forward to explain the causes and mechanisms leading to disorientation and (mass) strandings of sperm whales and other odontocetes (Evans 1997; Smeenk 1997; Tougaard \& Kinze 1999; Goold et al. 2002; Evans et al. 2005; Pierce et al. 2007; Vanselow \& Ricklefs 2005).

Animals are generally thought to possess a magnetic sense that they use e.g. for magnetic alignment (Červený et al. 2011; Begall et al. 2013), chronobiological processes as for the biological clock (Liboff 2014) and for orientation as on the migration routes of birds or cetaceans (Zoeger et al. 1981; Kirschvink et al. 1986; Phillips 1996; Wiltschko \& Wiltschko 1996; Kirschvink 1997; Walker et al. 2002; Lohmann et al. 2008; Kremers et al. 2014; Qin et al. 2016). These findings suggest that whales navigate using parameters of the Earth's magnetic field and most likely also its superimposed geomagnetic anomalies. Nevertheless, in the open sea depth maps often look very different from geomagnetic anomaly maps of the same area. The geomagnetic anomalies can give additional (mis)information for orientation for whales (Klinowska 1985, 1988; Walker et al. 1992) and other animals (Alerstam 1987; Lohmann et al. 2007; Wiltschko et al. 2009; Schiffner et al. 2011; Brothers \& Lohmann 2015). Failure of whales to account for disruptions in the magnetic field, such as those triggered by random and abrupt Solar storms, may thus lead to temporary navigational errors and disorientation (Vanselow \& Ricklefs 2005; Vanselow et al. 2009; Ferrari 2017). However, whales in the open sea presumably switch to a more reliable navigation system if they realize their orientation is wrong (as it is known from migrating birds (Wiltschko \& Wiltschko 1996)), so their mistake has no negative consequences.

From experiments with homing pigeons tracking their flights through two different magnetically influenced terrains it is known that they can experience problems in orientation if they fly across an unknown area with larger geomagnetic anomalies. These pigeons needed more time to reach their loft, e.g. after switching to other navigation mechanisms (Schiffner et al. 2011). Analogous observations were reported from migratory flights of birds across a strong magnetic anomaly in central Sweden (Alerstam 1987). The same problems may happen for migrating animals within a geomagnetic storm, because the effects on the magnetic information are comparable. Likewise, Schreiber \& Rossi $(1976,1978)$ compared pigeon races and sunspot numbers (a measure for Solar activity) and found a negative correlation between the homecoming rate and Solar activity and a positive one for flight duration and Solar activity. Ferrari \& Tautz (2015) reported an influence of Solar storms on the homing behaviour of honey bees. They found a 2.7 times greater loss of incoming to outgoing bees to a hive at days with geomagnetic storms compared with days without storms. Greatest bee losses occurred during the longest and most severe storms.
Vanselow \& Ricklefs (2005) examined the possible relationship between Solar activity and sperm whale strandings in the North Sea and found a positive correlation between the frequency of strandings over the centuries and the length of Solar cycles. Vanselow et al. (2009) also studied the relationship between strandings and yearly aa-index values. The aa-index is a global geomagnetic activity index determined from the magnetic field parameter at two antipodal magnetic observatories in England and Australia. The authors associated sperm whale strandings with navigational errors resulting from confusion between local geomagnetic anomalies and temporal geomagnetic field perturbations caused by Solar storms, which both have comparable magnitudes. Such navigational errors in the southern part of the Norwegian Sea may cause whales to stray into the North Sea. The North Sea is a sandy and very shallow $15-150 \mathrm{~m}$ deep basin that becomes progressively shallower towards the south, with extensive sandbanks, gently sloping sandy beaches, mudflats and estuaries, with a wide tidal range. Sperm whales are adapted to living in the open ocean in deep water and therefore have problems navigating and feeding in these shallow waters. The relatively frequent occurrence of strandings around the basin has led the North Sea to be referred to as a 'sperm whale trap' (Smeenk 1997; Vanselow \& Ricklefs 2005).

However, sperm whale strandings in the North Sea are irregular occurrences and periods of relatively frequent strandings have been interspersed with periods during which hardly any strandings have been reported (Smeenk 1997). Pierce et al. (2007) tried to explain these variations on the basis of climatic changes. They found a weak but significant positive correlation between the occurrence of warmer periods and the frequency of sperm whale strandings in the North Sea. This might be associated with changes in the distribution of squid species and consequent changes in the whales' northern feeding grounds, but the effects of temperature on the sperm whale's main prey item in the north-eastern Atlantic, G. fabricii, is currently unknown.

Long-term changes in seawater temperature may have been influenced historically by variations in Solar activity (Thejll \& Lassen 2000; Jiang et al. 2015). In addition, Solar storms can also affect magnetic field parameters directly, with effects that may last for hours or even days. Solar storms are mostly triggered by coronal mass ejections. The storms contain higher amounts of charged particles and radiation compared with the normal Solar wind ejected by the sun. Particles in Solar storms move much faster, with velocities from several hundred up to $1000 \mathrm{~km} \mathrm{~s}^{-1}$. These high-energy particles may be released towards the Earth during a coronal mass ejection, hitting and deforming the Earth's magnetic field. These charged particles will also be deflected by the magnetosphere, as a result of the Lorentz force and follow the magnetic field lines towards the polar regions where they are aligned almost perpendicular to the Earth's surface and the highly energetic particles thus penetrate into the ionosphere and upper atmosphere. Collisions with ionospheric particles may then produce auroras (polar lights), which represent the prominent visible effect of Solar storms. Auroras appear in the same area (auroral oval) that 
is subject to the largest geomagnetic field deformations during a Solar storm. Powerful geomagnetic storms can lead to manifold phenomena, such as failures in communication systems and satellites, large-scale power blackouts and pipeline fires. In this context, also connections between astronomical phenomena and terrestrial life are conceivable, even if directly the Earth's magnetic field is deflecting extraterrestrial particles. So it seems reasonable that Solar storms may impact the magnetic senses of many migrating species.

In this study, we evaluated the possible factors responsible for altering sperm whale migratory behaviour in the Norwegian Sea, particularly in the area around Shetland and the deep Norwegian Channel, through which sperm whales may stray south into the North Sea. We do not focus on the magnetic sense itself but on the effects on navigation of magnetic variations (of the Earth's magnetic dipole field (30 $000 \mathrm{nT}$ at the equator and $70000 \mathrm{nT}$ at the poles (nT = nanotesla); steady) and/or of local spatial magnetic deviations caused by the nature of the Earth's crust called geomagnetic anomalies (up to some $100 \mathrm{nT}$; steadily overlaying the dipole field) and/ or of temporal small geomagnetic variations caused by Solar storms (up to some $100 \mathrm{nT}$; highly time variable) but less by even smaller magnetic variations caused by the daily Solar tidal force on free electrons in the ionosphere $(20-50 \mathrm{nT}$; Solar tidal oscillation used by animals as biological clock (Liboff 2014)). Possible interactions and its consequences are discussed, including temporal and spatial aspects of regional conditions.

\section{Materials and methods}

Figure 1 gives an overview of the study area ranging from the Norwegian Sea down to the Azores. It contains the locations of the sperm whale strandings in the southern North Sea in early 2016. These strandings have been well documented (Clemens et al. 2016; Evans 2016; Unger et al. 2016).

We collected data on geomagnetic field parameters (magnetic field intensity, inclination (vertical angle at the Earth's surface between the magnetic field vector and the horizontal plane) and declination (horizontal angle between magnetic north and geographic north)) in the areas between Shetland and Norway and the North Sea and Norwegian Sea from the magnetometer measuring station at Solund, Norway $\left(61.08^{\circ}\right.$ $\mathrm{N}, 4.84^{\circ} \mathrm{E}$ ), which was the nearest station to the area under discussion. Magnetometer data were obtained from the Tromsø Geophysical Observatory (UiT - The Arctic University of Norway, N-9037 Tromsø, Norway) at http://flux.phys.uit.no/ stackplot/, by inputting the magnetic parameters and locations.

Spatial distances corresponding to magnetic field intensity and inclination angle variations observed in Solund were derived on the basis of local spatial gradients in the International Geomagnetic Reference Field (IGRF) (Thébault et al. 2015) for $61^{\circ} \mathrm{N}, 3^{\circ} \mathrm{E}$ on 1 January 2016. This position is about $100 \mathrm{~km}$ west of Solund. The data were obtained from NOAA's National Centers for Environmental
Information (NCEI) at http://www.ngdc.noaa.gov/geomagweb.

\section{Results}

Sperm whale strandings at the beginning of 2016

The chronology of 29 sperm whale strandings in the North Sea at the beginning of 2016 was as follows: 8 January, two animals at Wangerooge (Lower Saxony, Germany); 12 January, two near Helgoland (Schleswig-Holstein, Germany) and five at Texel (The Netherlands); 13 January, one animal near Büsum (Schleswig-Holstein, Germany) and one at the mouth of the Weser (Lower Saxony, Germany); 14 January, one animal at Texel (The Netherlands); 22 January, one animal (two escaped) at Old Hunstanton (Norfolk, UK); 24 January, three animals near Skegness (Lincolnshire, UK); 25 January, one animal at Wainfleet (Lincolnshire, UK); 31 January, eight animals near Kaiser-Wilhelm-Koog (Schleswig-Holstein, Germany); 2 February, one animal near Calais (France); 3 February, two animals near Büsum (Schleswig-Holstein, Germany) and one at Old Hunstanton (Norfolk, UK). Some of these strandings were recorded as live-strandings (Clemens et al. 2016; Evans 2016; Unger et al. 2016). Twenty-two dissected sperm whales were well nourished and their stomach contained high amounts of squid beaks, fish bones and otoliths, fed 'shortly' before stranding (Unger et al. 2016). The squid beaks were mainly from G. fabricii (U. Piatkowski personal communication). Accordingly, Unger et al. (2016) conclude from their thorough investigations with the statement that the sperm whales have swam the wrong way and stranded.

\section{Effects of Solar storms on geomagnetic field parameters between Shetland and Norway}

Prior to the mass sperm whale strandings at the beginning of 2016, magnetometer readings at the measuring station at Solund for 20/21 December 2015 (Fig. 2(a)) and 31 December 2015/1 January 2016 (Fig. 2(b)) for 18 and 28 h, respectively, recorded changes in the magnetic field structures for the region. Sperm whales may thus have lost their way in this area around Solund.

The spatial distances corresponding to magnetic field intensity and inclination angle variations with latitude or longitude were determined at the entrance to the Norwegian Channel $\left(61^{\circ} \mathrm{N}, 3^{\circ} \mathrm{E}\right)$. The Earth's magnetic dipole field intensity (measured in nanotesla (nT); undisturbed (without disturbances by Solar storms e.g.)) was 51118 nT on 1 January 2016, the intensity gradients were $195 \mathrm{nT}(100 \mathrm{~km})^{-1}$ in north-south (calculated from $60^{\circ} \mathrm{N}, 3^{\circ} \mathrm{E}$ with a magnetic field intensity of $50899 \mathrm{nT}$ and $62^{\circ} \mathrm{N}, 3^{\circ} \mathrm{E}$ with $51332 \mathrm{nT}$, here $2^{\circ}$ difference on Earth's surface correspond to a distance of $222 \mathrm{~km}$ ) and $29 \mathrm{nT}(100 \mathrm{~km})^{-1}$ in east-west direction (calculated from $61^{\circ} \mathrm{N}, 1^{\circ} \mathrm{E}$ with $51092 \mathrm{nT}$ and $61^{\circ} \mathrm{N}, 5^{\circ} \mathrm{E}$ with $51155 \mathrm{nT}$, here $4^{\circ}$ difference correspond to a distance of $216 \mathrm{~km}$ ). The inclination angle was $73.23^{\circ}$ and the inclination gradients were $0.55^{\circ}(100 \mathrm{~km})^{-1}$ in north-south and $0.03^{\circ}(100 \mathrm{~km})^{-1}$ in eastwest direction (same calculation conditions as for intensity; 


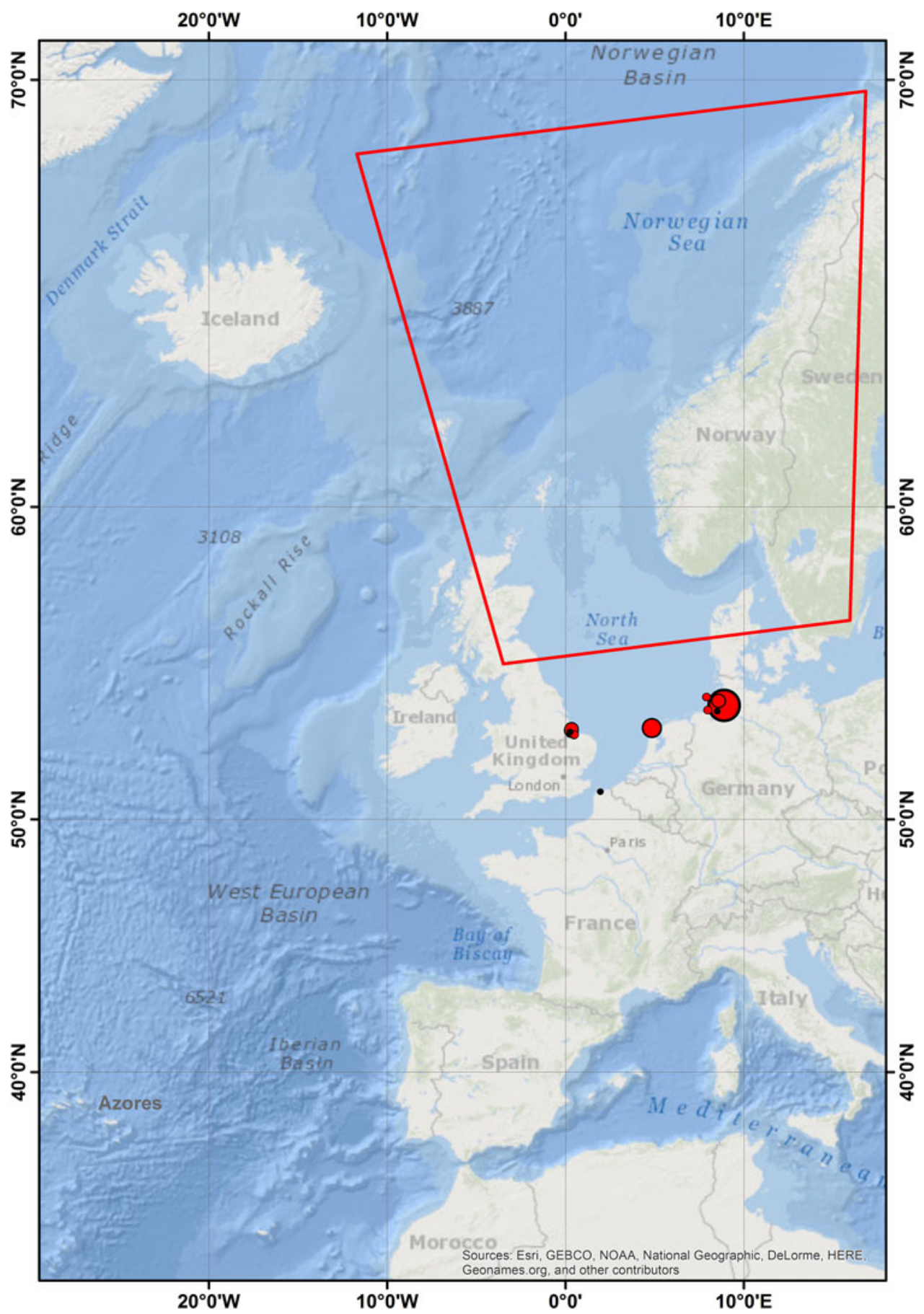

Fig. 1. Overview map of the area of interest from the Norwegian Sea to the Azores. The strandings at the southern coastline of the North Sea in early 2016 are marked: black dot $\triangleq 1$ stranding, red filled circles $\triangleq 2$ strandings, great red filled circles $\triangleq 3$ strandings, larger red filled circle $\triangleq 6$ strandings, largest red filled circle $\triangleq 8$ strandings. The red marked square gives the surrounding of the geomagnetic anomalies map shown in Fig. 3 . Map image was created using $\operatorname{ArcGIS}^{\circledR}$ software by Esri.

appropriate north-south values are $73.83^{\circ}$ and $72.62^{\circ}$ and east-west values are $73.20^{\circ}$ and $73.27^{\circ}$ ).

During the first Solar storm, the magnetic field intensity of $51150 \mathrm{nT}$ increased to a maximum of $51450 \mathrm{nT}$, followed by a decrease to $50520 \mathrm{nT}$, representing an absolute magnetic difference within $18 \mathrm{~h}$ of $>900 \mathrm{nT}$ (Fig. 2(a)), which is comparable with a theoretical north-south distance of $>460 \mathrm{~km}$ in the area between Shetland and Norway. A second Solar storm began on 31 December 2015, resulting in fluctuations of $+230 \mathrm{nT}$ followed by $-310 \mathrm{nT} 10 \mathrm{~h}$ later, with an absolute magnetic difference within $28 \mathrm{~h}$ of $540 \mathrm{nT}$ (Fig. 2(b)), equivalent to a deviation in latitude of $277 \mathrm{~km}$.

In addition to changes in magnetic field intensity, the declination and inclination of the geomagnetic field lines in relation 

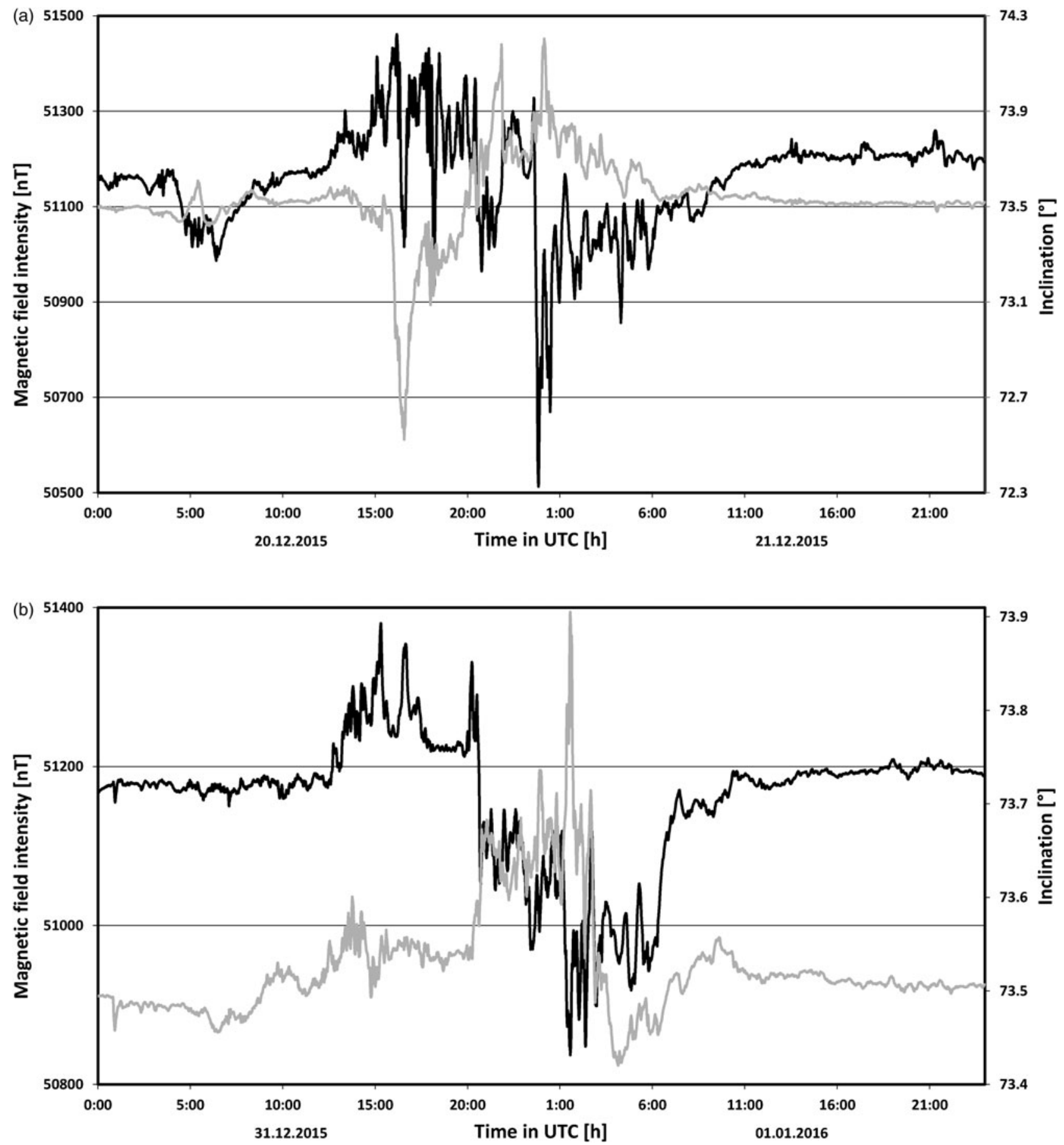

Fig. 2. 'Magnetic field intensity' (black) and 'inclination' (grey) values obtained from the magnetometer station at Solund (Norway). Changes in these magnetic parameters over 2 days within two Solar storms: (a) from 20-21 December 2015 over $18 \mathrm{~h}$ and (b) from 31 December 2015 to 1 January 2016 over $28 \mathrm{~h}$. Vertical axes values of (a) and (b) show great differences. The axis spreading from (a) to (b) is 2 for intensity and 4 for inclination. Data from Tromsø Geophysical Observatory (UiT - The Arctic University of Norway) at http://flux.phys.uit.no/stackplot/.

to the geographic conditions also change abruptly during Solar storms. Inclination is known to be an important navigation parameter for birds (Dennis et al. 2007) and may therefore also be used by whales. At Solund, the inclination fell immediately from $73.49^{\circ}$ before the first storm to $72.53^{\circ}$, and then increased to $74.18^{\circ} 8 \mathrm{~h}$ later, before returning to the initial level
(Fig. 2(a)). This Solar storm-related absolute difference of about $1.65^{\circ}$ in inclination in the region of Solund was comparable with a latitude difference of about $300 \mathrm{~km}$ $\left(1.65^{\circ} / 0.55^{\circ} \times 100 \mathrm{~km}\right)$. The second Solar storm on 31 December 2015/1 January 2016 is shown in Fig. 2(b). During this storm, the inclination rose to $73.90^{\circ}$ and then fell to $73.42^{\circ}$, 


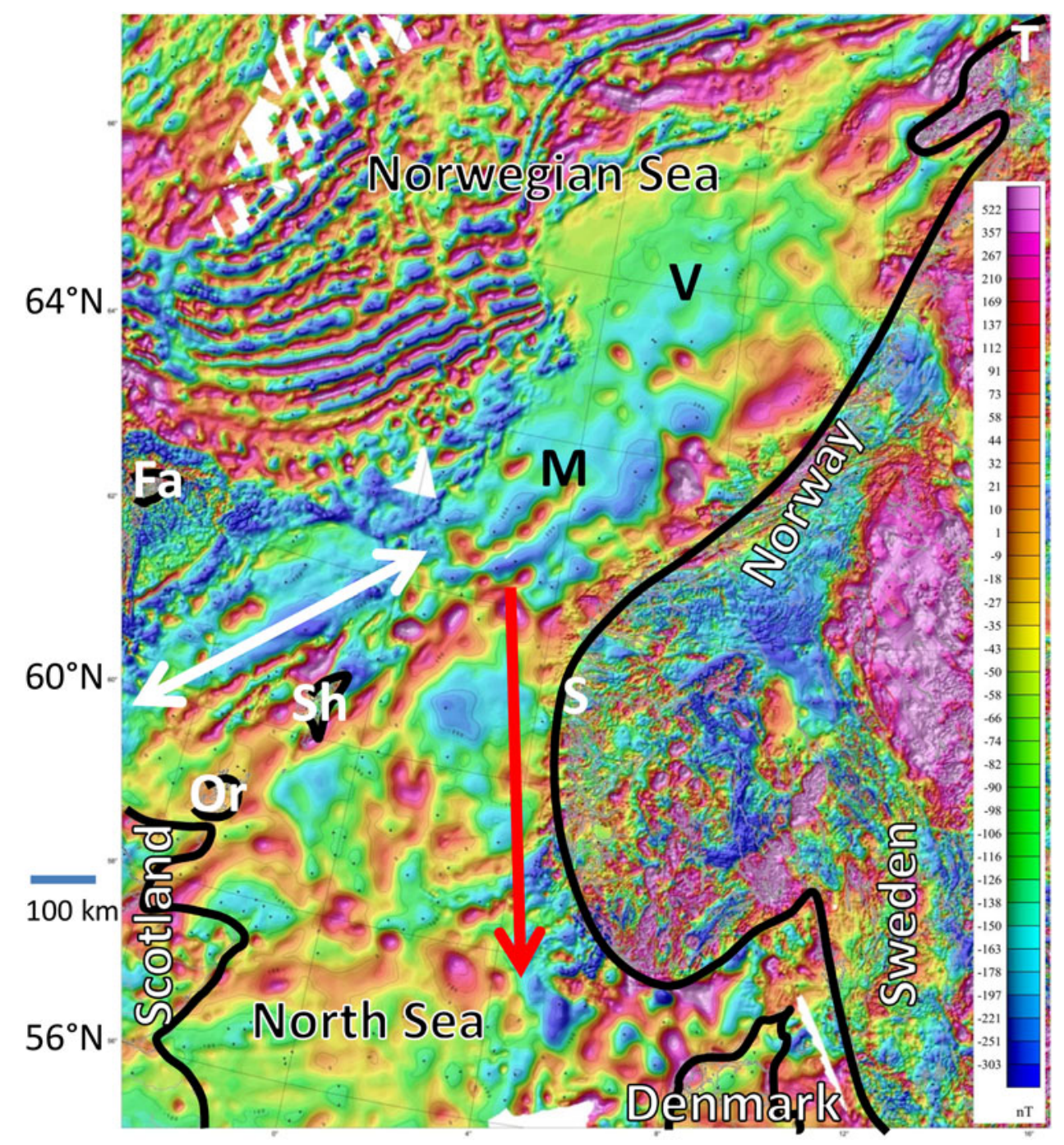

Fig. 3. Geomagnetic anomalies between Scotland and Norway. Data were collected from 0 to $500 \mathrm{~m}$. Colours indicate strengths of anomalies, ranging from -303 (dark blue) to $+522 \mathrm{nT}$ (violet). Møre Basin and Vøring Basin are marked by a black M and V. White markers show Solund (S), Tromsø (T) and the Islands Faroe (Fa), Shetlands (Sh) and Orkneys (Or). Black lines indicate coastlines and islands. The correct sperm whale migration route is indicated by a white arrow (Faroe-Shetland Channel) and the misguided route by a red arrow (Norwegian Channel).

Figure modified from Olesen et al. (2010a, b). The map contains data under Norwegian license for public data (NLOD) made available by the Geological Survey of Norway (NGU).

with an absolute difference of $0.48^{\circ}$, equivalent to a deviation in latitude of $87 \mathrm{~km}$. This second storm was not as heavy as the first, but lasted for much longer.

\section{Spatial extent of geomagnetic anomalies}

Depth profile and magnetic dipole field information can be used for orientation at sea but also spatial geomagnetic anomalies (with up to $2 \%$ of the magnetic dipole field intensity) overlaying the undisturbed magnetic dipole field. Spatial geomagnetic variations caused by magnetic anomalies in the area between Shetland and Norway and around the Møre Basin north of Solund resemble magnetic mountains, with magnetic intensities ranging from -200 to $+300 \mathrm{nT}$ on average (Fig. 3). These geomagnetic 'hills' range from 50 to $150 \mathrm{~km}$ in diameter. A sperm whale could cross such a 'hill' in about 1 day, at a mean travel speed of around $4 \mathrm{~km} \mathrm{~h}^{-1}$ (Jaquet \& Whitehead 1999). Geomagnetic anomalies of up to more than $+400 \mathrm{nT}$ (representing the crest of a geomagnetic 'hill') between Shetland and north of Solund represent a natural, approximately $\sim 100 \mathrm{~km}$-wide geomagnetic 'mountain chain' acting as a 'psychological barrier' to the south (North Sea, Fig. 3). South of this thought 'barrier' lies a geomagnetic 'trough' comparable with the normal, more northerly migration route (white arrow in Fig. 3).

\section{Geomagnetic storm intensity changes with latitude}

The intensity of geomagnetic storms triggered by Solar eruptions varies with latitude. The variations in magnetic field intensity caused by the first Solar storm on 20 December 2015, as detected at the magnetometer measuring stations in Tromsø 
and Solund in Norway, Brorfelde in Denmark and Vienna in Austria, are shown in Fig. 4. The intensity of the deviations in the magnetic field caused by the Solar storm was dramatically reduced at lower latitudes, with almost no detectable effect at $48^{\circ} \mathrm{N}$ (Vienna, Austria) (Fig. 4).

\section{Discussion}

Female sperm whales live their whole lives at lower latitudes, between $40^{\circ} \mathrm{N}$ and $40^{\circ} \mathrm{S}$ (Rice 1989), where they raise their calves. In contrast, male sperm whales migrate to feed at higher latitudes, such as the Norwegian Sea, after weaning. Young male sperm whales therefore grow up in lower latitudes with geomagnetic anomalies, but a quiet, largely undisturbed geomagnetic field, which they may learn to use for navigation. However, at these latitudes they have no experience of random, abrupt geomagnetic storms generated by the impact of coronal mass ejections. In areas such as the Azores, at latitudes of approximately $40^{\circ} \mathrm{N}$ to $40^{\circ} \mathrm{S}$, the magnetic field lines are more horizontal and the effect of Solar-driven magnetic storms is therefore minimal. However, Solar-induced geomagnetic storms may have greater impacts on sperm whales as they begin to migrate further north or south. In higher latitudes, magnetic field lines have a greater vertical component. In the Norwegian Sea, magnetic field distortions can be of the same magnitude as the geomagnetic anomalies themselves. During heavier Solar storms, Solar-driven distortions in the order of these geomagnetic anomalies between Shetland and Norway and around the Møre Basin may cause sperm whales in that area to become disoriented. If they do not compensate by switching from their magnetic sense to an alternative mode of navigation (only few navigation systems can be used in the deep sea such as bathymetry or the Sun), they may become stranded along the shallow and tidally influenced North Sea coasts, after continuing to misguidedly swim south for a week or more (assuming a mean travel speed of $\sim 4 \mathrm{~km} \mathrm{~h}^{-1}$ (Jaquet \& Whitehead 1999), it would take $\sim 10$ days or more to cover a distance of about $1000 \mathrm{~km}$; e.g. the shortest distance Solund-Büsum is $820 \mathrm{~km}$ ). Younger bulls are more likely to be misled by Solar storms, because they have not yet learnt how to adapt to possible temporary and abrupt magnetic disturbances at higher latitudes.

If whales possess a magnetic sense, it may be either directional, i.e. sensitive to the direction and orientation of the Earth's magnetic field, or scalar, i.e. sensitive to the absolute magnetic field strength. Both direction and magnitude are disturbed during geomagnetic storm events, resulting in potential disorientation whichever mode they employ. Inclination and other directional magnetic field components are characteristic for a specific location and perturbations in these vector contributions could therefore affect the animal's determination of their geographic position. Vector distortions (e.g. in the declination) could also result in animals taking an aberrant course, comparable with a compass misreading. In contrast, variations in magnetic field intensity will only result in errors in determining the animal's position and subsequent course deviations would be caused by the animal compensating for their perceived new position. Given that the maximal horizontal angular variation in the magnetic field vector during geomagnetic storms is only a few degrees, while the directional deviation necessary to cause a whale to swim accidently into the North Sea is much higher, it seems more likely that the animals are rather using the magnetic field to determine their position in this case. However, seemingly erratic variations in magnetic field direction and intensity can cause major confusion and may thus lead to course corrections as a result of disorientation, rather than conscious, yet incorrect adjustments.

Analysis showed that spatial changes in intensity and inclination of the magnetic field (including the effects of spatial geomagnetic anomalies) between Shetland and Norway as well as geomagnetic deviations (triggered by the Solar storms in December 2015 and January 2016) indicate the same pattern for whales traversing from north to south (spatial distances up to some $100 \mathrm{~km}$ and temporal up to some days). In other words: Whales may be disoriented when spatial geomagnetic anomalies generate the same magnetic pattern (over time while crossing that area) as the temporary magnetic pattern caused by a geomagnetic storm. This could result in fatal navigation errors, if the whales swim through the geomagnetic 'mountain chain' between Shetland and Solund (Norway) without taking account of it. A deviation from the migration route of $\sim 100 \mathrm{~km}$ to the south or north can have a major impact; the geomagnetic information may make the whales think that they are on the right side (north) of the thought 'barrier', when they are actually on the wrong (south) side due to the Solar storm.

For basins with no or only a few local geomagnetic anomalies, such as in the northern part of the Møre Basin and the north-eastern Vøring Basin, the variation in the magnetic field could be interpreted as a geographic shift in latitude. The magnetic intensity gradient in the area amounts $\geq 195$ $\mathrm{nT}(100 \mathrm{~km})^{-1}$ (in north-south direction) and hence the magnetic perturbation could have caused the animals to miscalculate their position significantly. An initial increase in intensity, as observed on 31 December 2015, could be interpreted as indicating a more northerly position, which would therefore be compensated for by following a more southerly course. The field strength decrease during the second phase of the event should have had the opposite effect. It is also possible that the temporal dip in magnetic field magnitude might have concealed the crossing of a positive magnetic 'mountain chain' south of the usual migration route. But nevertheless, also considering only the dipole field of the Earth without any distortion by a geomagnetic anomaly, the short-term disturbance of the magnetic field intensity by the Solar storm results in a shift of up to $460 \mathrm{~km}$ and of the inclination of up to $300 \mathrm{~km}$ in north-south direction, which could explain itself the misguided migration of the whales in that area.

Cochran et al. (2004) reported that birds (Catharus thrushes) calibrate their magnetic orientation in line with the setting sun once a day. If this behaviour also applies to whales, disruption of the geomagnetic field by a Solar storm at the crucial time of magnetic adjustment at the sea surface could result in the whales following a wrong course for a whole day 


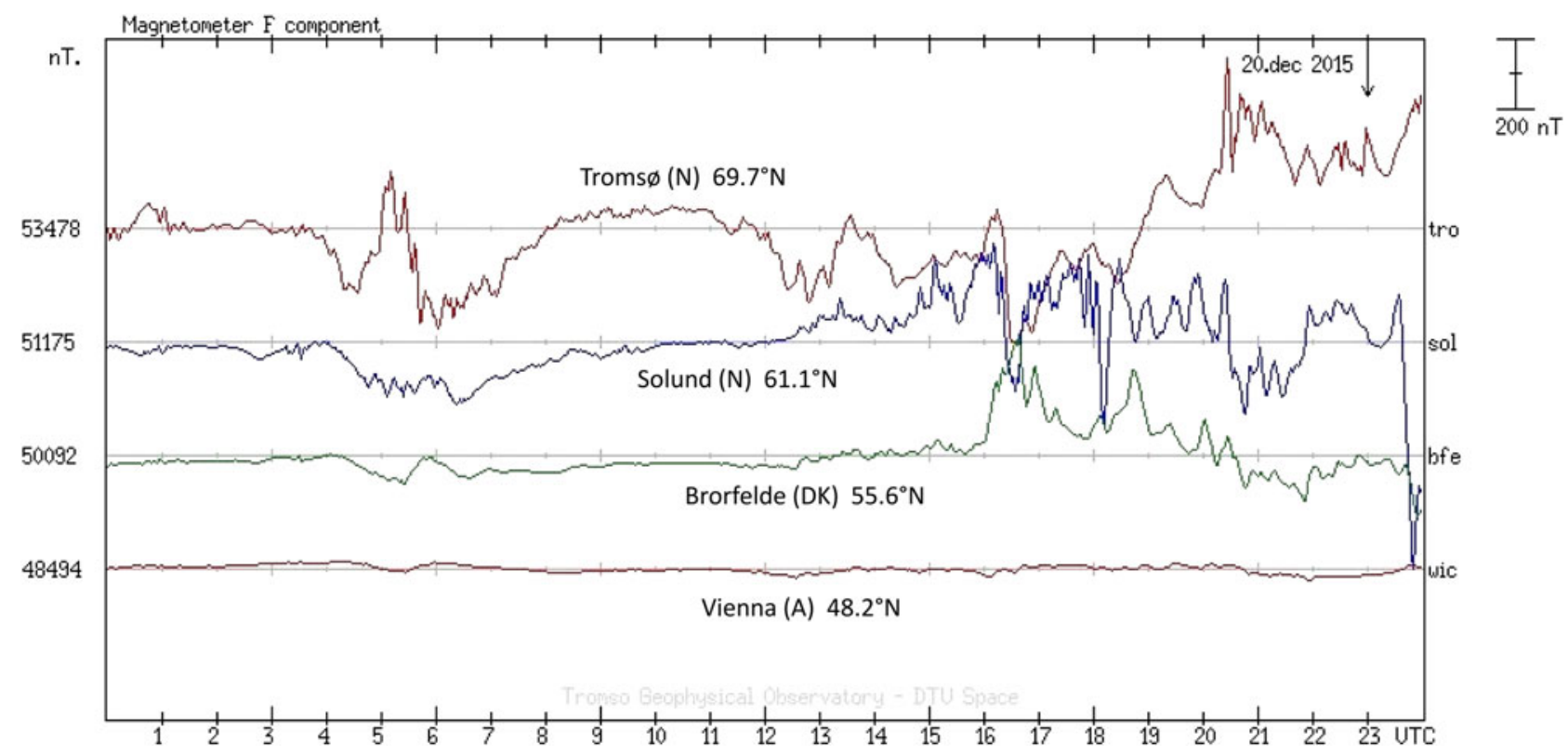

Fig. 4. Changes in magnetic field intensities within the magnetic storm beginning on 20 December 2015 at different latitudes. Original graph modified from Tromsø Geophysical Observatory (UiT - The Arctic University of Norway) website at http://flux.phys.uit.no/stackplot/.

( $\sim 100 \mathrm{~km}$ ), potentially causing them to swim into the shallow North Sea, with the observed consequences.

The strength of Solar storms also can be a criterion for the vehemence of confusion. Weaker Solar storms can cause geomagnetic distortions in the range of natural in the moving environment of whales occurring pattern. Accordingly, the probability of disorientation may decrease with more powerful Solar storms, because the animals may then more easily recognize the mistake in terms of magnetic navigation. Liboff (2014) discussed for chronobiological processes a possible chronodisruptive effect of weak magnetic fields or weak Solar storms in the range of 20-50 nT.

All possible considerations and aspects mentioned here, alone or in combination, can lead to a temporary disorientation of the whales on their migration route. If this route is too close to the North Sea, this disorientation can become dangerous for these mammals in the manner described above. In contrast, if sperm whales are far away from any coast or shallow water they normally have time enough to change their navigation (system) without any consequences.

Vanselow \& Ricklefs (2005) previously examined the frequency and duration of Solar cycles over 300 years and Vanselow et al. (2009) analysed the yearly aa-index over 400 years to identify positive relationships between their occurrence and the frequency of sperm whale strandings in the North Sea. Magnetic storms triggered by the sun that reaches the Earth have the potential to affect whales and their orientation systems and the probability of these events is higher within short Solar cycles, at Solar cycle maxima and during time periods with high aa-indices.

The astronomical-biological approach that Solar storms may contribute to sperm whale strandings persists. Support for a causal relationship between cetacean strandings and geomagnetic storms ranges from long-term statistical correlations with Solar activity, to documented coincidences for single events. In this context, the stranding of 29 sperm whales early in 2016 might have been triggered by the Solar storms recorded on 20/21 December 2015 and 31 December 2015/1 January 2016, which also caused the auroras observed at the same time over northern Europe. The current findings thus offer a plausible explanation of the phenomenon of sperm whale strandings, especially in the North Sea and may also be of relevance to other animals migrating through comparable areas.

\section{Acknowledgements}

We thank the Tromsø Geophysical Observatory and especially Johnsen Magnar Gullikstad and Holmeslet Børre Heitmann for geomagnetic data, Katharina Witte for generating the first figure and Andrea Fais, Klaus Ricklefs and Anne Mareike Vanselow for helpful discussions. Especially we thank Chris Smeenk for rewriting parts of the Introduction and for critical comments on the manuscript and Susan Furness for providing linguistic support.

\section{References}

Alerstam, T. (1987). Bird migration across a strong magnetic anomaly. J. Exp. Biol. 130, 63-86.

Begall, S., Malkemper, E.P., Červený, J., Němec, P. \& Burda, H. (2013). Magnetic alignment in mammals and other animals. Mamm. Biol. 78, $10-20$.

Brothers, J.R. \& Lohmann, K.J. (2015). Evidence for geomagnetic imprinting and magnetic navigation in the natal homing of sea turtles. Curr. Biol. 25, 392-396. 
Červený, J., Begall, S., Koubek, P., Nováková, P. \& Burda, H. (2011). Directional preference may enhance hunting accuracy in foraging foxes. Biol. Lett. 7, 355-357.

Clemens, T., Hartmann, A. \& Ulber, J. (2016). Pottwal-Drama an der Nordseeküste. Natur- und Umweltschutz, Zeitschrift der Naturschutzund Forschungsgemeinschaft. Der Mellumrat e.V. 15, 13-24.

Cochran, W.W., Mouritsen, H. \& Wikelski, H. (2004). Migrating songbirds recalibrate their magnetic compass daily from twilight cues. Science 304 , 405-408.

Dennis, T.E., Rayner, M.J. \& Walker, M.M. (2007). Evidence that pigeons orient to geomagnetic intensity during homing. Proc. R. Soc. B-Biol. 274, $1153-1158$.

Evans, K., Thresher, R., Warneke, R.M., Bradshaw, C.J.A, Pook, M., Thiele, D. \& Hindell, M.A. (2005). Periodic variability in cetacean strandings: links to large-scale climate events. Biol. Lett. 1, 147-150.

Evans, P. (2016). Largest sperm whale stranding ever recorded in the North Sea. Sea Watch Foundation (online since 10.02.2016). http://www. seawatchfoundation.org.uk/largest-sperm-whale-stranding-ever-recordedin-the-north-sea/.

Evans, P.G.H. (1997). Ecology of sperm whales (Physeter macrocephalus) in the Eastern North Atlantic, with special reference to sightings \& strandings records from the British Isles. Bull. Inst. R. Sci. Nat. Bel. Biol. 67(Suppl.), $37-46$.

Ferrari, T.E. (2017). Cetacean beachings correlate with geomagnetic disturbances in Earth's magnetosphere: an example of how astronomical changes impact the future of life. Int. J. Astrobiol. 16, 163-175.

Ferrari, T.E. \& Tautz, J. (2015). Severe Honey Bee (Apis mellifera) Losses correlate with geomagnetic and proton disturbances in Earth's atmosphere. Astrobiol. Outreach 3, 134.

Goold, J.C., Whitehead, H. \& Reid, R.J. (2002). North Atlantic sperm whale, Physeter macrocephalus, strandings on the coastlines of the British Isles and Eastern Canada. Can. Field-Naturalist 116, 371-388.

Jaquet, N. \& Whitehead, H. (1999). Movements, distribution and feeding success of sperm whales in the Pacific Ocean, over scales of days and tens of kilometers. Aquat. Mamm. 25, 1-13.

Jiang, H. et al. (2015) Solar forcing of Holocene summer sea-surface temperatures in the northern North Atlantic. Geology 43, 203-206.

Kirschvink, J.L. (1997). Magnetoreception: homing in on vertebrates. Nature 390, 339-340.

Kirschvink, J.L., Dizon, A.E. \& Westphal, J.A. (1986). Evidence from strandings for geomagnetic sensitivity in cetaceans. J. Exp. Biol. 120, 1-24.

Klinowska, M. (1985). Cetacean live stranding sites relate to geomagnetic topography. Aquat. Mamm. 1, 27-32.

Klinowska, M. (1988). Cetacean navigation and the geomagnetic field. $J$. Navigation 41, 52-71.

Kremers, D., Marulanda, J.L., Hausberger, M. \& Lemasson, A. (2014). Behavioural evidence of magnetoreception in dolphins: detection of experimental magnetic fields. Naturwissenschaften 101, 907-911.

Liboff, A.R. (2014) Why are living things sensitive to weak magnetic fields? Electromagn. Biol. Med. 33, 241-245.

Lohmann, K.J., Lohmann, C.M.F. \& Putman, N. (2007). Magnetic maps in animals: nature's GPS. J. Exp. Biol. 210, 3697-3705.

Lohmann, K.J., Lohmann, C.M.F. \& Endres, C.S. (2008). The sensory ecology of ocean navigation. J. Exp. Biol. 211, 1719-1728.

Olesen, O. et al. (2010a). New aeromagnetic and gravity compilations from Norway and adjacent areas - methods and applications. In: Vining, B.A. and Pickering, S.C. (eds) Petroleum Geology: From Mature Basins to new Frontiers. Proceedings of the 7th Petroleum Geology Conference. Geology Society, London, pp. 559-586.

Olesen, O., Gellein, J., Gernigon, L., Kihle, O., Koziel, J., Lauritsen, T., Mogaard, J.O., Myklebust, R., Skilbrei, J.R. \& Usov, S. (2010b).
Magnetic anomaly map, Norway and adjacent areas. Scale 1:3 million, Geological Survey of Norway. http://www.ngu.no/upload/Kart og data/ Geofysikkart stort format/Mag_3_mill.pdf.

Phillips, J.B. (1996). Magnetic navigation. J. Theor. Biol. 180, 309-319.

Pierce, G.J., Santos, M.B., Smeenk, C., Saveliev, A. \& Zuur, A.F. (2007). Historical trends in the incidence of strandings of sperm whales (Physeter macrocephalus) on North Sea coasts: an association with positive temperature anomalies. Fish. Res. 87, 219-228.

Qin, S. et al. (2016). A magnetic protein biocompass. Nat. Mater. 15, $217-$ 226.

Rice, D.W. (1989). Sperm whale. Physeter macrocephalus linnaeus, 1758. In: Ridgway, S.H. \& Harrison, R. (eds), Handbook of Marine Mammals, River Dolphins and the Larger Toothed Whales, vol. 4, pp. 177-233. Academic Press, London.

Schiffner, I., Fuhrmann, P. \& Wiltschko, R. (2011) Tracking pigeons in a magnetic anomaly and in magnetically 'quiet' terrain. Naturwissenschaften 98, 575-581.

Schreiber, B. \& Rossi, O. (1976). Correlation between race arrivals of homing pigeons and solar activity. Bolletino di zoologia 43:3, 317-320.

Schreiber, B. \& Rossi, O. (1978). Correlation between magnetic storms due to solar spots and pigeon homing performances. IEEE Trans. Magn., 14, 961-963.

Smeenk, C. (1997). Strandings of sperm whales (Physeter macrocephalus) in the North Sea: history and patterns. Bull. Inst. R. Sci. Nat. Bel. Biol., 67(Suppl.), 15-28.

Steiner, L., Lamoni, L., Plata, M.A., Jensen, S.-K., Lettevall, E. \& Gordon, J. (2012). A link between male sperm whales, Physeter macrocephalus, of the Azores and Norway. J. Marine Biol.l Assoc. UK 92, 1751-1756.

Thébault, E. et al. (2015). International geomagnetic reference field: the 12th generation. Earth Planet. Space 67, 79.

Thejll, P. \& Lassen, K. (2000). Solar forcing of the Northern hemisphere land air temperature: new data. J. Atmos. Sol. Terr. Phys. 62, 1207-1213.

Tougaard, S. \& Kinze, C.C. (eds) (1999). Proceedings from the Workshop Sperm Whale Strandings in the North Sea. The Event - the Action - the Aftermath, pp. 1-25. Fisheries and Maritime Museum, Esbjerg, Biological Papers 1.

Unger, B., Rebolledo, E.L.B., Deaville, R., Gröne, A., Ijsseldijk, L.L., Leopold, M.F., Siebert, U., Spitz, J., Wohlsein, P. \& Herr, H. (2016). Large amounts of marine debris found in sperm whales stranded along the North Sea coast in early 2016. Mar. Pollut. Bull. 112, 134-141.

Vanselow, K.H. \& Ricklefs, K. (2005). Are solar activity and sperm whale Physeter macrocephalus strandings around the North Sea related? J. Sea Res. 53, 319-327.

Vanselow, K.H., Ricklefs, K. \& Colijn, F. (2009). Solar driven geomagnetic anomalies and sperm whale (Physeter macrocephalus) strandings around the North Sea: an analysis of long term datasets. Open Mar. Biol. J. 3, 89-94.

Walker, M.M., Kirschvink, J.L., Ahmed, G. \& Dizon, A.E. (1992). Evidence that fin whales respond to the geomagnetic field during migration. J. Exp. Biol. 171, 67-78.

Walker, M.M., Dennis, T.E. \& Kirschvink, J.L. (2002). The magnetic sense and its use in long-distance navigation by animals. Curr. Opin. Neurobiol. 12, 735-744.

Wiltschko, R., Schiffner, I. \& Wiltschko, W. (2009). A strong magnetic anomaly affects pigeon navigation. J. Exp. Biol. 212, 2983-2990.

Wiltschko, W. \& Wiltschko, R. (1996). Magnetic orientation in birds. J. Exp. Biol. 199, 29-38.

Zoeger, J., Dunn, J.R. \& Fuller, M. (1981). Magnetic material in the head of the common Pacific dolphin. Science 213, 892-894. 